\title{
Polycystic Ovarian Syndrome: Correlation between clinical hyperandrogenism, anthropometric, metabolic and endocrine parameters
}

\author{
Ayesha Khan ${ }^{1}$, Nasim Karim², \\ Jahan Ara Ainuddin ${ }^{3}$, Muhammad Faisal Fahim ${ }^{4}$
}

\begin{abstract}
Objective: To evaluate the correlation between clinical hyperandrogenism-hirsutism assessed by modified Ferriman-Gallwey (F-G) score, anthropometric, metabolic and endocrine parameters among PCOS infertile women.

Methods: This observational study after approval of FRC \& ERC of BUMDC was conducted from September 2018-March 2019. It included seventy women aged 20-40 years who presented in infertility clinic of a local Hospital in Karachi. After written informed consent participants were enrolled as per the inclusion criteria of the study and evaluated for cyclical pattern (oligomenorrhoea, amenorrhoea, polymenorrhea), physical (weight, height, BMI), anthropometric, (waist circumference, hip circumference, waist to hip ratio, hirsutism), metabolic (carbohydrate, lipid \& protein) and endocrine parameters (serum FSH, LH, LH/ FSH ratio, serum testosterone, prolactin and progesterone level). Hirsutism was assessed by visual method through modified F-G score and Pearson correlation was determined between hirsutism and other study parameters.
\end{abstract}

Results: A positive Pearson correlation is found between hirsutism and body weight, BMI, waist and hip circumference, waist to hip ratio (WHR), very low density lipoprotein, cholesterol, triglycerides and testosterone levels.

Conclusion: Hirsutism has correlation with anthropometric, metabolic and hyperandrgenic disorders in PCOS infertile women as assessed by modified F-G score.

KEYWORDS: PCOS, Hirsutism, F-G score, Correlation, Anthropometric parameters, Metabolic parameters, Endocrine parameters.

doi: https://doi.org/10.12669/pjms.35.5.742

How to cite this:

Khan A, Karim N, Ainuddin JA, Fahim MF. Polycystic Ovarian Syndrome: Correlation between clinical hyperandrogenism, anthropometric, metabolic and endocrine parameters. Pak J Med Sci. 2019;35(5):1227-1232.

doi: https://doi.org/10.12669/pjms.35.5.742

This is an Open Access article distributed under the terms of the Creative Commons Attribution License (http://creativecommons.org/licenses/by/3.0), which permits unrestricted use, distribution, and reproduction in any medium, provided the original work is properly cited.

Correspondence:

Dr. Ayesha Khan, MBBS.

Senior Lecturer, M Phil student,

Department of Pharmacology,

Bahria University Medical and Dental College,

Adjacent PNS Shifa,

DHA Phase II,

Karachi, Pakistan.

E-mail: dr.ayeshakhan85@gmail.com

* Received for Publication

* Revision Received:

* Revision Accepted:
March 19, 2019

June 19, 2019

June 24, 2019

\section{INTRODUCTION}

Polycystic ovary syndrome (PCOS) is an endocrine disease of females commonly present during reproductive life. The pathophysiology of this disease mainly includes chronic anovulation, hyperandrogenemia, and insulin resistance which may present clinically as abnormal uterine bleeding, hirsutism, infertility etc. Prevalence of PCOS varies from $5 \%$ to $10 \%$ in reproductive age group females. ${ }^{1}$ The most applicable tool to diagnose PCOS worldwide is revised Rotterdam criteria 2003. ${ }^{2}$ 
PCOS has multiple origins but exact cause is still unknown. The disease develops due to excessive production of androgens by ovaries along with excessive release of insulin and luteinizing hormone (LH). Hyperinsulinemia causes increase gonadotrophin releasing hormone $(\mathrm{GnRH})$,reverses $\mathrm{LH} / \mathrm{FSH}$ ratio such as to $3: 1$ or $2: 1$, increases level of androgen and decreases production of sex hormone-binding globulin (SHBG). ${ }^{3}$ Insulin resistance associated with excessive insulin level can cause metabolic abnormalities which are characteristic feature of this syndrome. ${ }^{4}$ Obesity, decreased sensitivity of insulin, pre-diabetes, type II diabetes, cardio-metabolic and psychological features such as anxiety, depression etc. are the main metabolic features present in PCOS patients ${ }^{5,6}$

Hirsutism is a condition characterized by excessive hair growth in androgen-dependent areas of the body. Hairs become coarse and are distributed over the androgen dependent areas in male pattern. The etiology of hirsutism is mainly classified as: idiopathic, androgenic and nonandrogenic. Eighty percent of the females of reproductive age group, who present to clinical settings with hirsutism, most commonly have PCOS. ${ }^{7}$ It has been documented that about $70-80 \%$ of hirsute women have PCOS while non-androgenic factors are relatively rare. ${ }^{8}$

A lot of hair follicles are distributed all over the body surface but their number remains constant throughout individual's life. The size of follicles and texture of hair can vary in response to various factors and availability of androgen. Thus hirsutism reflects the interaction between concentration of androgen within the circulation and the sensitivity of the hair follicle to androgens. Process of keratinization, increased size of hair follicle, diameter of fiber and the time period of terminal hairs in the anagen phase all depend upon androgen. However, stimulation of hair growth depends on degradation and variation in sensitivity of organs to androgens in circulation and also on insulin resistance. ${ }^{9}$

The grading of hirsutism was described in 1961 by Ferriman and Gallwey through a simple scoring system. According to this scoring system, terminal hairs of eleven different sites of body are graded from zero-four with a cumulative score of thirty six. However in modified Ferriman and Gallwey (mFG) score number of body sites is reduced to nine after excluding forearm and lower leg. Absence of hirsutism is indicated by a score of less than eight,

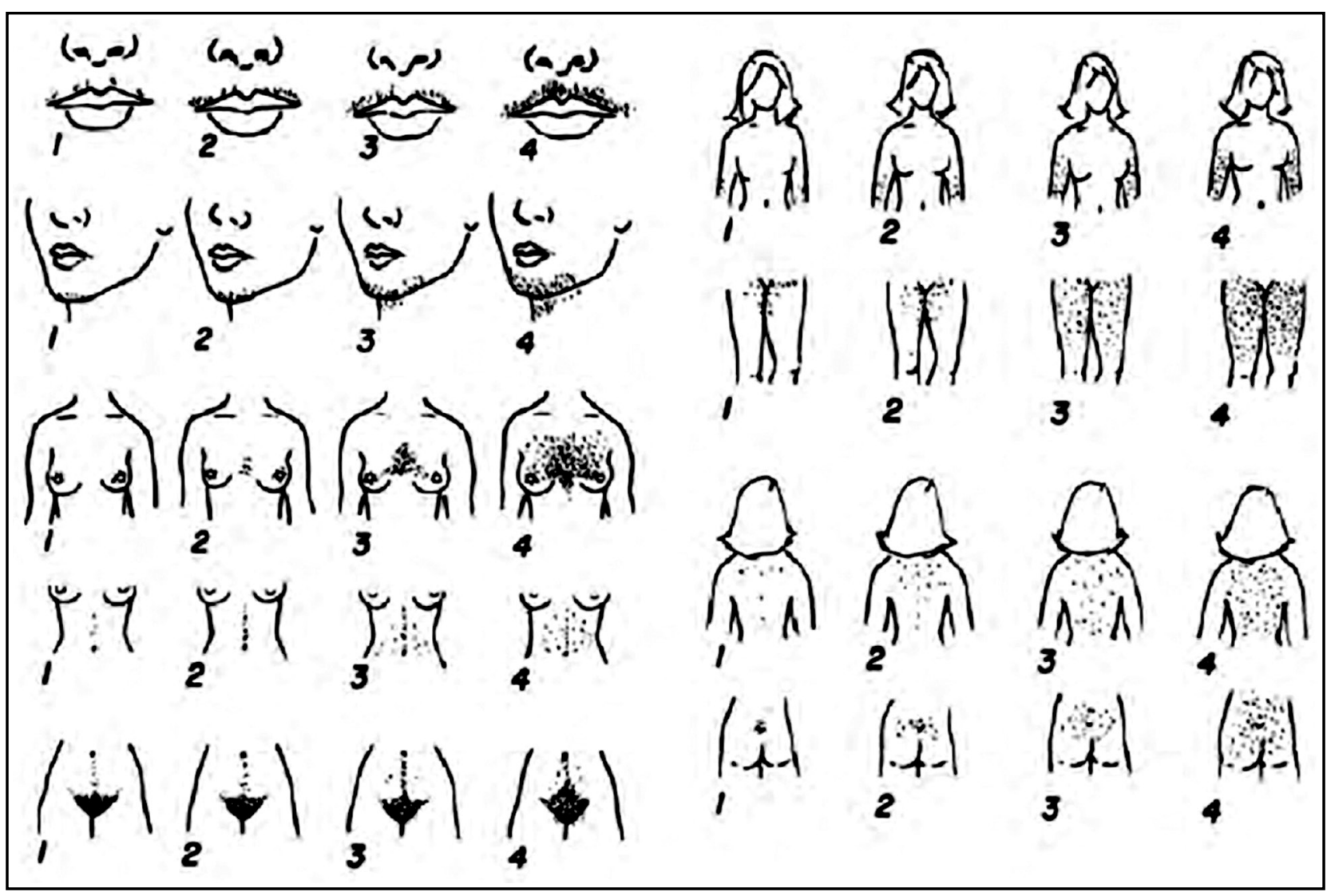

Fig.1: Modified Ferriman-Gallwey Score (mFG score $\left.{ }^{10}\right)$. 
mild hirsutism is equal to a score of eight-sixteen, moderate is seventeen-twenty four and finally a score more than twenty four indicates severe type of hirsutism. ${ }^{4}$ Fig. $1 .{ }^{10}$

Positive correlation was found in most of the studies between hirsutism, anthropometric, metabolic and endocrine parameters present in patients with PCOS. Present study was designed to correlate hirsutism with anthropometric, metabolic and endocrine parameters in local PCOS infertile women as documented local literature is scarce on this aspect of PCOS.

\section{METHODS}

This observational study is a part of an ongoing randomized open prospective clinical trial for MPhil research work. After approval (FRC/BUMDC/ Phar/004/) from Faculty Research Committee \& Ethical Review Committee (ERC 51/2018) dated: 24-09-2018, of Bahria University Medical \& Dental College (BUMDC), the study was conducted from September 2018 to March 2019. It included seventy patients who presented in Infertility clinic of Obstetrics \& Gynecology outpatient department of Mamji Hospital Karachi were enrolled. Written informed consent was taken from each participant. Inclusion criteria was: infertile women 20-40 years of age, cyclical problems of oligomenorrhoea / amenorrhoea / polymenorrhea, hirsutism, fasting hyperinsulinemia $(>10 \mu \mathrm{U} / \mathrm{mL}$, fasting plasma glucose $(<7 \mathrm{mmol} / \mathrm{L}$ or $126 \mathrm{mg} / \mathrm{dl})$. Exclusion criteria was: women having primary amenorrhoea, perimenopausal women, concomitant medical problems as diabetes, hepatic or renal insufficiencies, tumors of pituitary, ovary or adrenal gland, women using oral contraceptives / injectables and females undergone oophorectomy/ovarian ablation therapy. All patients were evaluated for:

(A) Cyclical pattern: upon history of patient for infertility (failure to achieve a successful pregnancy after 12 months or more of appropriate, timed unprotected intercourse) ${ }^{11}$ oligomenorrhoea (menstrual cycles greater than 35 or 45 days in length, which in turn translates into 8 or less cycles and 10 or less cycles per year respectively), ${ }^{12}$ amenorrhoea (absence of menstruation for more than three cycles or absence of menstruation for greater than six months) ${ }_{1}^{13}$ polymenorrhea (refers to cyclic bleeding that is normal in terms of volume but occurs at too frequent intervals of less than 21 days). ${ }^{14}$

(B) Physical $\mathcal{E}$ anthropometric parameters (weight, height, BMI, waist circumference, hip circumference, waist/hip ratio, hirsutism).
Body weight was taken on weighing machine without shoes and extra clothing. Height was evaluated by measuring tape. Quetelets Index formula was used to calculate BMI. Quetelets Index formula is:

$$
\mathrm{BMI}=\frac{\text { Weight }(\mathrm{kg})}{\text { Height }^{2}\left(\mathrm{~m}^{2}\right)}
$$

Waist circumference was calculated as the minimum circumference between the iliac crest and the lateral costal margin, whereas the hip circumference was calculated as the maximum circumference over the gluteal region (buttocks), with a measuring tape according to 2003 criteria of WHO.

Waist/hip ratio (waist circumference/hip circumference) was calculated as per Asian criteria waist: hip ratio $>$ or $=0.80$ in women was considered indicator of obesity. ${ }^{15}$ Hirsutism was detected by using modified Ferriman - Gallwey score. The method to assess hirsutism by the scoring of terminal hairs in nine body areas, named upper lip, chin, chest, upper abdomen, lower abdomen, upper back, lower back, thighs \& upper arms. ${ }^{4}$

(C) Venous blood was taken after overnight fast of 12-14 hours for determination of (I) Metabolic parameters: (a) Carbohydrate Metabolism (fasting serum glucose, fasting serum insulin level, glucose/insulin ratio)(b) Lipid Metabolism (high density lipoprotein, low density lipoprotein, very low density lipoprotein, cholesterol, triglyceride, (c)Protein Metabolism (serum hs-CRP) and (II) Endocrine parameters: (serum FSH, LH, LH/ FSH ratio, serum testosterone, prolactin and progesterone level).

(D) Pearson correlation between Ferriman-Gallwey score for hirsutism, anthropometric, metabolic and endocrine parameters was applied to evaluate the positive or negative relationship in terms of significance.

Sample size \& Statistical analysis: Sample size was calculated by "Comparing Two Means" on www.Openepi.com. Frequencies and percentages are calculated for categorical data while mean with standard deviation is documented for continuous variables. Pearson correlation is evaluated between hirsutism and continuous variables and $\mathrm{P}<0.05$ is considered significant. Data analysis is performed by statistical software package SPSS version 23 .

\section{RESULTS}

Physiological, anthropometric, metabolic (carbohydrate, lipid and protein metabolism) and endocrine parameters are sown in Table-I. Mean weight, BMI, WHR, modified Ferriman-Gallwey scoring, 
Table-I: Parameters in study patients $(\mathrm{N}=70)$.

\begin{tabular}{|c|c|}
\hline $\begin{array}{l}\text { A) Physiological } \mathcal{E} \text { Anthropometric } \\
\text { Parameters }\end{array}$ & Mean $\pm S D$ \\
\hline Age (Years) & $28.71 \pm 5.237$ \\
\hline Weight (kg) & $71.49 \pm 10.75$ \\
\hline Height (m) & $1.587 \pm .0410$ \\
\hline $\mathrm{BMI}\left(\mathrm{Kg} / \mathrm{m}^{2}\right)$ & $28.45 \pm 4.178$ \\
\hline Waist Circumference $(\mathrm{cm})$ & $92.05 \pm 12.831$ \\
\hline Hip Circumference (cm) & $109.11 \pm 10.044$ \\
\hline WHR & $0.84 \pm .0517$ \\
\hline $\begin{array}{l}\text { Modified Ferriman-Gallwey } \\
\text { Scoring System }\end{array}$ & $9.07 \pm 1.753$ \\
\hline \multicolumn{2}{|l|}{ B) Metabolic Parameters } \\
\hline \multicolumn{2}{|l|}{ 1. Glucose Metabolism } \\
\hline Fasting serum glucose $(\mathrm{mg} / \mathrm{dl})$ & $99.31 \pm 8.823$ \\
\hline Fasting serum insulin $(\mu \mathrm{IU} / \mathrm{ml})$ & $13.97 \pm 5.492$ \\
\hline \multicolumn{2}{|l|}{ 2. Lipid Metabolism } \\
\hline High density lipoprotein ( & $42.74 \pm 2.019$ \\
\hline Low density lipoprotein $(\mathrm{mg} / \mathrm{dl})$ & $111.74 \pm 24.63$ \\
\hline Very low density lipoprotein (mg/dl) & $36.61 \pm 18.70$ \\
\hline Serum Cholesterol (mg/dl) & $178.46 \pm 32.07$ \\
\hline Serum Triglyceride (mg/dl) & $162.97 \pm 52.88$ \\
\hline \multicolumn{2}{|l|}{ 3. Protein Metabolism } \\
\hline Serum hs-CRP (mg/L) & $6.01 \pm 1.827$ \\
\hline \multicolumn{2}{|l|}{ C) Endocrine Parameters } \\
\hline Serum FSH (mIU/ml) & $3.974 \pm 1.248$ \\
\hline Serum LH $(\mathrm{mIU} / \mathrm{ml})$ & $10.81 \pm 2.805$ \\
\hline $\mathrm{LH} / \mathrm{FSH}$ & $2.885 \pm .235$ \\
\hline Serum Testosterone (ng/dl) & $78.57 \pm 18.27$ \\
\hline Serum Prolactin (ng/ml) & $17.99 \pm 9.276$ \\
\hline Serum Progesterone $(\mathrm{ng} / \mathrm{ml})$ & $1.312 \pm .5635$ \\
\hline Serum TSH $(\mu \mathrm{IU} / \mathrm{ml})$ & $1.898 \pm .9675$ \\
\hline
\end{tabular}

Values represented as mean + standard deviation. BMI: body mass index,

WHR: Waist-hip ratio, LH: Luteinizing hormone, FSH: Follicle stimulating hormone.

fasting serum insulin, low density lipoproteins, triglycerides, hs-CRP and testosterone levels are found to be higher than the standard cut off values. Whereas fasting serum glucose level is towards the higher side. Serum FSH \& LH ratio is reversed with LH level almost three times more than the FSH level. Serum progesterone level is well below the normal ovulation range indicating anovulation.

As regards the cyclical pattern majority 40 (57.14\%) patients had oligomenrrhea followed by $22(31.43 \%)$ patients with amenorrhea Fig.2 and Table-II. Mild hirsutism was found in 59 patients, 01 had moderate while 10 had normal distribution of hairs.

Pearson correlation between clinical hyperandrogenism (as per modified Ferriman-
Table-II: Cyclic pattern in study patients $(\mathrm{N}=70)$.

\begin{tabular}{lcc}
\hline Cyclic pattern & No. of patients & Percentage \\
\hline Oligomenorrhea & 40 & $57.14 \%$ \\
Amenorrhea & 22 & $31.43 \%$ \\
Normal cycle & 4 & $5.714 \%$ \\
Polymenorrhea & 4 & $5.714 \%$ \\
\hline Total & 70 & 99.998 \\
\hline
\end{tabular}

Gallwey score) anthropometric, metabolic and endocrine parameters was determined. A positive correlation is found between hirsutism and body weight, BMI, waist and hip circumference, WHR, very low density lipoprotein, cholesterol, triglycerides and testosterone levels Table-III.

\section{DISCUSSION}

The syndrome of polycystic ovaries is a widespread endocrine disease found in females during reproductive age. The underlying cause of this disease includes chronic anovulation, increased

Table-III: Pearson correlation between Ferriman-Gallwey score and anthropometric, metabolic and endocrine parameters $(\mathrm{N}=70)$.

\begin{tabular}{lcc}
\hline Variable & Correlation " $r$ " & P-value \\
\hline Age & 0.020 & 0.872 \\
weight & 0.546 & 0.000 \\
Height & 0.250 & 0.037 \\
BMI & 0.501 & 0.000 \\
waist circumference & 0.468 & 0.000 \\
Hip circumference & 0.475 & 0.000 \\
WHR & 0.397 & 0.001 \\
Fasting Serum Glucose & 0.040 & 0.741 \\
Fasting Serum Insulin & 0.102 & 0.401 \\
High Density Lipoprotein & 0.075 & 0.538 \\
Low Density Lipoprotein & 0.166 & 0.171 \\
Very Low Density Lipoprotein & 0.339 & 0.004 \\
Serum Cholesterol & 0.430 & 0.000 \\
Serum Triglyceride & 0.346 & 0.003 \\
Serum hs-CRP & 0.130 & 0.284 \\
Serum FSH & -0.108 & 0.373 \\
Serum LH & -0.199 & 0.098 \\
LH/FSH & -0.076 & 0.534 \\
Serum Testosterone & 0.797 & 0.000 \\
Serum Prolactin & -0.042 & 0.732 \\
Serum Progesterone & 0.097 & 0.422 \\
Serum TSH & 0.205 & 0.089 \\
\hline Significant $<0.05 . B M I ~$ &
\end{tabular}

Significant $\mathrm{p}<0.05$. BMI: body mass index,

WHR: Waist-hip ratio,

hs-CRP: high sensitivity C-reactive protein,

LH: Luteinizing hormone,

FSH: Follicle stimulating hormone,

r: Pearson correlation coefficient. 


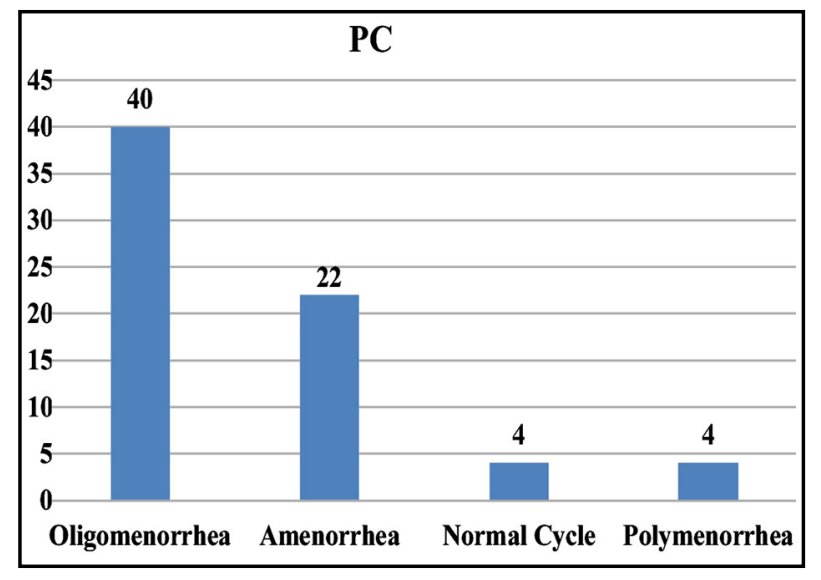

Fig.2: Cyclical pattern.

androgen level in the blood, and decreased sensitivity to insulin leading to abnormal uterine bleeding, hirsutism, and infertility. Prevalence of PCOS in reproductive-aged women varies from $4 \%$ to $7 \%{ }^{2}$ Mean age of patients in our study was $28.71 \pm 5.237$ years which is coinciding with the finding of Usmani and collegues. ${ }^{16}$

International BMI cut-off point as recommended by $\mathrm{WHO}$ for obesity is $\geq 25 \mathrm{~kg} / \mathrm{m}^{2}$. As per this criteria our patients were obese with a mean BMI of $28.45 \pm 4.178 .{ }^{17}$ Hirsutism is found in $70 \%$ of women with PCOS. ${ }^{18}$ Approximately $80 \%$ to $85 \%$ of women with hyperandrogenism clinically have PCOS. ${ }^{19}$ We used hirsutism score as a diagnostic criteria of clinical hyperandrogenism and $85 \%$ (60 out of 70 ) patients in our study had hirsutism.

PCOS women have increased secretion of $\mathrm{LH}$ pulse frequency and also have increased level of LH in comparison to FSH in circulation that is the ratio between FSH and LH reverses. There is commonly oligomennorrhea followed by amenorrhea. ${ }^{20}$ Our study results coincides with these findings as 40 $(57.14 \%)$ out of 70 patients had oligomenrrhea followed by $22(31.43 \%)$ patients with amenorrhea. LH level was almost three times more than the FSH.

Excess of insulin cause anovulation, immature luteinisation of follicles, arrest the development of follicles, which is represented clinically by fasting hyperinsulinemia and low level of serum progesterone accounting for anovulatory infertility. ${ }^{21}$ The same is evident from our study data.

Aswini has documented in her study, waist circumference $\geq 88 \mathrm{~cm}, \mathrm{HDL}$ cholesterol $<50 \mathrm{mg}$ / $\mathrm{dl}$ and serum TG $\geq 150 \mathrm{mg} / \mathrm{dl}^{.22}$ These findings are in favor of our study however we also have found very low density lipoproteins higher than the normal values in our study group.
According to Joint Interim Statement (JIS) criteria, meeting at least 3 of the criteria $(\mathrm{WC} \geq 80 \mathrm{~cm}$, FPG $\geq 100 \mathrm{mg} / \mathrm{dl}, \mathrm{TG} \geq 150 \mathrm{mg} / \mathrm{dl}$, HDL-C W $<50 \mathrm{mg} /$ $\mathrm{dl}$ ) is diagnostic of metabolic syndrome. ${ }^{23}$ Since our patients met all four criteria so they had metabolic syndrome, which is part and parcel of PCOS.

Sales et al. ${ }^{24}$ have documented a positive Pearson correlation between F-G score, BMI and abdominal circumference. This indicates that obesity and adiposity in abdominal area correlates with hirsutism. F-G score may be a utilized as a tool to evaluate the association between hyperandrogenism and cardiovascular risk factors that is the lipid level in PCOS women. A positive correlation is found in our study between hirsutism and body weight, BMI, waist and hip circumference, WHR, very low density lipoprotein, cholesterol, triglycerides and testosterone levels, as per statistically significant evaluation by Pearson correlation. This is coinciding with the finding of Sales et al. ${ }^{24}$ However they have found a positive correlation with insulin level and a negative correlation with testosterone level which is in contrast to our results. This may be due to difference in study populations on geographical basis. Negative correlation was found in our study between F-G score and serum hs-CRP which is coinciding with the finding of Ganie et al. ${ }^{25}$

\section{Limitations of study:}

1. This is a single centre study.

2. Free testosterone and DHEAS have not estimated due to budget constraints.

\section{CONCLUSION}

Hirsutism has correlation with anthropometric, metabolic and hyperandrogenic disorders in PCOS infertile women as assessed by modified F-G score. Modified Ferriman-Gallwey score may be used as a marker to evaluate these disorders in PCOS infertile women on account of existence of positive correlation between hirsutism and them.

\section{RECOMMENDATIONS}

Multicentric studies with large sample size in our local population may be undertaken to authenticate our findings and to generate data at the level of Pakistan.

Acknowledgements: The authors are highly thankful to all study participants who consented and spared valuable time for this study.

Conflict of interest: None.

Grant Support E Financial Disclosures: None. 


\section{REFERENCES}

1. Hu L, Shen $\mathrm{H}, \mathrm{Wu} \mathrm{QF}$, Tian L, Hu MH. Treatment of polycystic ovarian syndrome with insulin resistance by insulin-sensitizer. Clin Exp Obstet Gynecol. 2014;41:288-292.

2. Indhavivadhana $S$, Rattanachaiyanont $M$, Wongwananuruk $\mathrm{T}$. Hyperandrogenemia is associated with thin endometriumin reproductive-aged Thai women with polycystic ovary syndrome. Asian Biomed. 2013;7(4):545551. doi: 10.5372/1905-7415.0704.210.

3. Mihailidis J, Dermesropian R, Taxel P, Luthra P, GrantKels JM. Endocrine evaluation of hirsutism. Int J Women Dermatol. 2015;1(2):90-94. doi: 10.1016/j.ijwd.2015.04.003.

4. Tanwar S, Khilnani G. A clinical comparative study on the effects of metformin and pioglitazone on clinical symptoms in cases of polycystic ovarian syndrome (PCOS). Int J Basic Clin Pharmacol. 2016;5:98-104. doi: 10.18203/23192003. ijbcp20160108.

5. Yildiz BO, Bozdag G, Yapici Z, Esinler I, Yarali H. Prevalence, phenotype and cardio-metabolic risk of polycystic ovary syndrome under different diagnostic criteria. Hum Reprod. 2012;27(10):3067-3073. doi: 10.1093/humrep/des232.

6. Naderpoor N, Shorakae S, Courten B, Misso M L, Moran L J, Teede H J. Metformin and lifestyle modification in polycystic ovary syndrome: Systematic review and meta analysis, Human Reproduction Update. 2015;21( 5):560-574. doi: 10.1093/humupd/dmv025.

7. Messenger AG, de Berker DA, Sinclair RD. Disorders of hair. In: Burns T, Breathnach S, Cox N, Griffiths C, editors. Rook's Textbook of Dermatology. 8th ed. Vol. 4. West Sussex: Wiley-Blackwell; 2010.pp.66.80-89.

8. Wang ET, Kao CN, Shinkai K, Pasch L, Cedars MI, Huddleston HG. Phenotypic comparison of Caucasian and Asian women with polycystic ovary syndrome: A cross-sectional study, Fertil Steril. 2013;100(1):214-218.

9. Hohl A, Ronsoni MA, de Oliveira M. Hirsutism: Diagnosis and treatment. Arq Bras Endocrinol Metab. 2014; 58(2):97107. doi: 10.1590/0004-2730000002923.

10. Azziz R. Reproductive Endocrinology and Infertility: Clinical Expert Series Polycystic Ovary Syndrome. Obstet Gynecol 2018;132:321-336. doi: 10.1097/AOG.0000000000002698

11. Definitions of infertility and recurrent pregnancy loss: A committee opinion. Fertil Steril 2013;99:63. Practice Commit Am Soc Repro Med. doi: 10.1016/j.fertnstert.2012.09.023.

12. Sirmans SM, Pate K.A. Epidemiology and comorbidities of polycystic ovary syndrome in an indigent population. J Investig Med. 2014;62:868-874. doi: 10.1097/01. JIM.0000446834.90599.5d.

13. Andreeff $\mathrm{R}$, Amenorrhea. J Am Acad Phys Assist. 2014;27(10):50-51. doi: 10.1097/01. JAA.0000453871.15689.a2.

14. Rafique N, Alsheikh M. Prevalence of menstrual problems and their association with psychological stress in young female students studying health sciences. Saudi Med J. 2018;39(1):67-73. doi: 10.15537/smj.2018.1.21438.

15. Lean ME, Han TS, Morrison CE. Waist circumference as a measure for indicating need for weight management. BMJ. 1995;311:158-161.

16. Usmani A, Rehman R, Akhtar Z. Association of body mass index and dietary habits with ovarian and uterine morphology with subfertile polycystic ovarian syndrome. J Postgrad Med Inst. 2014;28(2):133-138.

17. Kim KS, Oh HJ, Choi YJ, Huh BW, Kim SK, Park SW, et al. Reappraisal of waist circumference cutoff value according to general obesity. Nutr Metab. 2016;13:26. doi: 10.1186/ s12986-016-0085-y.
18. Susan MS, Kristen AP. Epidemiology diagnosis and management of polycystic ovary syndrome. Clin Epidemiol. 2014;6:1-13.

19. Yau TL, Ng NY, Cheung LP, Ma RCW. Polycystic ovary syndrome: A common reproductive syndrome with long-term metabolic consequences Hong Kong Med J. 2017;23(6):622-634. doi: 10.12809/hkmj176308.

20. McCartney CR, Marshall JC. Clinical practice. Polycystic ovary syndrome. N Engl J Med. 2016;375;54-64.

21. Azziz R, Carmina E, Chen Z. Polycystic ovary syndrome. Nat Rev Dis Primers. 2016;2;1-18.

22. Aswini R, Jayapalan S. Modified Ferriman - Gallwey Score in Hirsutism and its Association with Metabolic Syndrome. Int J Trichol. 2017;9(1):7-13. doi: 10.4103/ijt.ijt_93_16.

23. Hu H, Kurotani K, Sasaki N, Murakami T, Shimizu C, Shimizu M, et al. Optimal waist circumference cut-off points and ability of different metabolic syndrome criteria for predicting diabetes in Japanese men and women: Japan Epidemiology Collaboration on Occupational Health. Study BMC Public Health. 2016;16:220. doi: 10.1186/s12889-016-2856-9.

24. Sales MF, Soter MO, Candido A L, Reis F M, Sousa M $\mathrm{O}$, Fernande AP et al. Ferriman-Gallwey Score correlates with obesity and insulin level in Polycystic Ovary Syndrome - an observational study. Rev Soc Bras Clin Med. 2015;13(2):107-110.

25. Ganie MA, Hassan S, Nisar S, Shamas N, Rashid A, Ahmed I, et al. High-sensitivity Creactive protein (hsCRP) levels and its relationship with components of polycystic ovary syndrome in Indian adolescent women with polycystic ovary syndrome (PCOS). Gynecol Endocrinol. 2014;30(11):781-784.

\section{Author's Contribution:}

AK: Principle investigator \& researcher. Collected and compiled the data, wrote the manuscript. NK: Supervisor of the study. Conceived the idea, provided intellectual guidance and proof read the manuscript.

JAA: Clinical supervisor of the study, provided clinical expertise and proof read the manuscript.

MFF: Provided statistical expertise.

\section{Authors:}

1. Dr. Ayesha Khan, MBBS. Senior Lecturer \& MPhil Student,

2. Prof. Dr. Nasim Karim, MBBS, MPhil, PhD, Post-Doc. Head of Department Pharmacology,

3. Prof. Dr. Jahan Ara Ainuddin, MBBS, MCPS, FCPS, PhD. Head of Department Obstetrics \& Gynecology, DIMC-DUHS, \& Consultant Obstetrician \& Gynecologist Mamji Hospital, Karachi, Pakistan.

4. Muhammad Faisal Fahim, Msc. Statistics. Statistician, Bahria University Medical \& Dental College, Karachi, Pakistan.

1, 2: Pharmacology Department, Bahria University Medical \& Dental College, Sailors Street, Adjacent PNS Shifa, Defence Phase II, Karachi, Pakistan. 